\title{
Standardization of Irrigation and Fertigation Requirement for Amaranthus under Polyhouse
}

\author{
A. J. Ajay Gokul ${ }^{1}{ }^{*}$, K. K. Shaheemath Suhara ${ }^{1}$ and P. S. Sheeja ${ }^{2}$ \\ ${ }^{1}$ Kerala Agricultural University, Thrissur, Kerala, India \\ ${ }^{2}$ Tamil Nadu Agricultural University, Coimbatore, Tamil Nadu, India \\ *Corresponding author
}

\section{A B S T R A C T}

\section{Keywords}

ETc, Fertigation, Amaranthus, RDF

\section{Article Info}

Accepted:

07 March 2020

Available Online:

10 April 2020

\begin{abstract}
A study was conducted in the Instructional Farm of PFDC, Tavanur, Kerala, during the period from November 2018 to February 2019 to Standardization of irrigation and fertigation requirement for amaranthus under polyhouse. Amaranthus variety CO1 was used for the study. Fertilizers were applied through drip irrigation system using venturi assembly. There were three levels of irrigations i.e., $\mathrm{I}_{1}-100 \%$ of ETc (crop evapotranspiration), $\mathrm{I}_{2}-80 \%$ of ETc and $\mathrm{I}_{3}-60 \%$ of ETc and three levels of fertigation viz: $\mathrm{F}_{1}-100 \%$ of Recommended Dose of Fertilizer (RDF), $\mathrm{F}_{2}-125 \%$ of RDF and $\mathrm{F}_{3}-150 \%$ of RDF. Crop parameters such as plant height, number of leaves and yield were noted during various crop growth stages for all the treatments. The treatment $\mathrm{I}_{2} \mathrm{~F}_{3}$ (Irrigation $80 \%$ of ETc and Fertigation $150 \%$ of RDF) showed comparatively better performance in yield characteristics as compared to the other treatments.
\end{abstract}

\section{Introduction}

Efficient use of available irrigation water and fertilizer is essential for increasing agricultural productivity for the alarming Indian population. Fertilizer management is the most important agro-technique, which controls development, yield and quality of a crop (Jisha, 2014). Fertilizer use efficiency is only 50 per cent in conventional practice of soil application (Sreya, 2018). Drip irrigation is a type of micro-irrigation system that has the potential to save water and nutrients by allowing water to drip slowly to the roots of plants, either from above the soil surface or buried below the surface. The goal is to place water directly into the root zone and minimize evaporation. The practice of application of water soluble fertilizers through irrigation water is termed as fertigation, which combines irrigation with water soluble fertilizer application is well recognized as the most effective and convenient means of maintaining optimum fertility level and water supply according to the specific requirement of each crop and soil, resulting in higher yields and better quality (Nirala et al., 2018). However, the fertilizers applied must be completely soluble in water and should not have any adverse effect on the crop. 
Polyhouse is a frame work structure covered by transparent material in order to protect the crops from adverse climate conditions such as wind, rain, radiation ETc. it provides a microclimate surrounding the crop that helps crops for maximum growth. Providing an optimum growing environment to the crops helps in production to its maximum levels.

Amaranth belongs to the family Amaranthaceae. It is the most popular leafy vegetable of Kerala. It can be grown throughout the year. The leaves and succulent stems are good sources of iron $(305 \mathrm{mg} / 100$ g), calcium (397 mg/100 g), vitamin A (8340 microgram /100 g)and vitamin C (99 mg /100 g). This study is an attempt to standardize irrigation and fertigation requirement for amaranthus under polyhouse.

\section{Materials and Methods}

The study was conducted using amaranthus during the months of November 2018 to February, 2019 under naturally ventilated polyhouse of PFDC, KCAET, Tavanur, Kerala. The site is situated on the cross point of $10^{\circ} 51^{\prime} 18^{\prime \prime} \mathrm{N}$ latitude and $75^{\circ} 59^{\prime} 11^{\prime \prime} \mathrm{E}$ longitude at an altitude of $8.54 \mathrm{~m}$ above mean sea level.

Naturally ventilated polyhouse of area $292 \mathrm{~m}^{2}$ (36 $\mathrm{m}$ in length and $8 \mathrm{~m}$ in width) is oriented in East-West direction. Its frame is made up of galvanized steel pipe and covered with 200 micron UV stabilized polyethylene film. Two sides are covered with insect proof net of 40 meshes for natural ventilation and protection against entry of insect pests.

The land inside the polyhouse was ploughed thoroughly using mini tiller and left idle for one week after lime application. Green amaranthus variety $\mathrm{CO} 1$ was used for the study. Seeds were treated with pseudomonas fluorescens (10 gram/litre) before sowing.
Seeds were germinated in plastic seedling trays and transplanted into the polyhouse on $25^{\text {th }}$ day. Beds were prepared inside polyhouse with $35 \mathrm{~m}$ length, $0.50 \mathrm{~m}$ width and $0.15 \mathrm{~m}$ height for double row planting. Plants were grown at row to row spacing of $0.45 \mathrm{~m}$ and plant to plant spacing of $0.30 \mathrm{~m}$. Intercultural operations were done manually in periodic manner.

The plants were irrigated daily through drip irrigation system. Irrigation water was pumped using 5hp monoblock pump set and conveyed through the main line of $63 \mathrm{~mm}$ diameter PVC pipes after filtering through the disc filter. From the main pipe, sub main of PVC pipes $(50 \mathrm{~mm})$ were installed. From the sub mains water is conveyed to LDPE laterals of diameter $16 \mathrm{~mm}$. Inline drippers at spacing of $40 \mathrm{~cm}$ were used for irrigation. Discharge rate of single dripper is $2 \mathrm{lph}$. Venturi injector was installed along with irrigation unit for fertigation. Duration of the crop was 120 days, so the fertigation was scheduled as 40 splits with the frequency of once in three days from planting till the end of crop. Weekly foliar application of micronutrients was also provided.

There were total nine experimental treatments including control with five replications. Three levels of irrigations ie, $\mathrm{I}_{1}-100 \%$ of ETc (crop evapotranspiration), $\mathrm{I}_{2}-80 \%$ of ETc and $\mathrm{I}_{3}$ $60 \%$ of ETc and three levels of fertigation viz: $\mathrm{F}_{1}-100 \%$ of Recommended Dose of Fertilizer (RDF), $\mathrm{F}_{2}-125 \%$ of $\mathrm{RDF}$ and $\mathrm{F}_{3}-$ $150 \%$ of RDF. KAU adhoc recommended fertigation was adopted as RDF. Plant height $(\mathrm{cm})$, number of leaves and yield $(\mathrm{kg})$ were recorded. The data was statistically analysed using Microsoft Excel. The level of significant difference (LSD at $\mathrm{P}<0.05$ ) was used in the ANOVA to test the effect of different treatments on different response variables. The data were presented as mean \pm SE. 


\section{Results and Discussion}

The treatment $\mathrm{I}_{2} \mathrm{~F}_{3}$ (Irrigation $80 \%$ of ETc and Fertigation $150 \%$ of RDF) showed comparatively better performance in yield as compared to the other treatments. $\mathrm{I}_{1} \mathrm{~F}_{1}$ resulted in significantly lowest yield among other treatments. $F_{3}$ resulted in higher yield in all levels of irrigation The highest plant height $(84 \mathrm{~cm})$, highest number of leaves (47 nos) and yield per plant $(0.12 \mathrm{~kg})$ was noticed in the irrigation level $80 \%$ of ETc and Fertigation $150 \%$ of RDF (Table 1).

Table.1 Yield performance

\begin{tabular}{|c|c|}
\hline Treatments & Total yield $(\mathbf{k g})$ \\
\hline $\mathbf{I}_{\mathbf{1}} \mathbf{F}_{\mathbf{1}}$ & $17.766^{\mathrm{d}}$ \\
\hline $\mathbf{I}_{\mathbf{1}} \mathbf{F}_{\mathbf{2}}$ & $30.029^{\mathrm{b}}$ \\
\hline $\mathbf{I}_{\mathbf{1}} \mathbf{F}_{\mathbf{3}}$ & $32.279^{\mathrm{b}}$ \\
\hline $\mathbf{I}_{\mathbf{2}} \mathbf{F}_{\mathbf{1}}$ & $30.304^{\mathrm{b}}$ \\
\hline $\mathbf{I}_{\mathbf{2}} \mathbf{F}_{\mathbf{2}}$ & $34.075^{\mathrm{b}}$ \\
\hline $\mathbf{I}_{\mathbf{2}} \mathbf{F}_{\mathbf{3}}$ & $38.875^{\mathrm{a}}$ \\
\hline $\mathbf{I}_{\mathbf{3}} \mathbf{F}_{\mathbf{1}}$ & $27.872^{\mathrm{c}}$ \\
\hline $\mathbf{I}_{\mathbf{3}} \mathbf{F}_{\mathbf{2}}$ & $30.232^{\mathrm{c}}$ \\
\hline $\mathbf{I}_{\mathbf{3}} \mathbf{F}_{\mathbf{3}}$ & $33.561^{\mathrm{b}}$ \\
\hline
\end{tabular}

The treatments were differed significantly with respect to yield. The results revealed that medium level of irrigation and higher dose of nutrients in the form of water soluble fertilizers led to higher yield. The higher dose of nutrients always resulted in significantly higher yield with different levels of irrigation. Medium level of irrigation and higher dose of nutrients might have served as optimum doses among these treatments. The results obtained could be attributed better growth and yield associated with optimum treatment. Hence drip fertigation with $80 \%$ of ETc and Fertigation of $150 \%$ of RDF has been standardised for cultivation of amaranthus under polyhouse of PFDC, KCAET, Tavanur, Kerala. Chantal et al., 2018 reported that among the three irrigation treatments $\mathrm{T} 1$ $(10 \%)$, treatment $\mathrm{T} 2(30 \%)$ and treatment $\mathrm{T} 3$ (60\%), for amaranth cultivation, treatment $\mathrm{T} 2$ of 30\% irrigation rate as the most significant and effective treatment. The results highlighted. Similar study on pigeonpea by Vanishree et al., 2019, revealed higher seed yield with drip fertigation of recommended nutrient dose using water soluble fertilizers (WSF) compared to other drip fertigation of water soluble and normal fertilizers at different levels of splits.

In conclusion the irrigation and fertilizer management is an important factor in crop production. Higher water application and inefficient fertilizer application is the current farming scenario, we should standardise the water and fertilizer application according to our area and mode of cultivation. Water use efficiency of the crops has to be increased in order to reduce the water loss from the field. Drip irrigation system is considered as the most effective micro irrigation method, as water is applied directly to the crop root zone. Hence it can be concluded that drip fertigation with $80 \%$ of ETc and Fertigation of $150 \%$ of $\mathrm{RDF}$ is best suited for cultivation of amaranthus under polyhouse.

\section{References}

Chantal, K., Ong'or, B.T.I. Hermenegilde, N., Melamce N. And Eliphase, B. 2018. 
Effects of Different Irrigation Rates on Growth and Yield Parameters of Amaranth. Int. J. Adv. Sci. Res. Eng. 4(9): 93-99

Jisha, A. R., C. 2014. Nutrient Use Efficiency and Economics of Salad Cucumber Using Drip Fertigation in Naturally Ventilated Polyhouse. IOSR J. Agric. Vet. Sci. 7(12): 22-25.

Nirala, S.K., Suresh, R. and Kumar, S. 2018. Fertigation Effect on Carnation under Polyhouse in North Bihar Agro-
Climatic Conditions. Int. J. Curr. Microbiol. App. Sci. 7(8): 3746-3755.

Sreya, U. P., 2018. Customized Fertilizer Formulation. Int. J. Chem. Stud. 6(6): 2144-2153.

Vanishree, H., Anand, N., Chittapur, B.M., Umesh, M.R. and Bhat, S.N. 2019. Standardization of Fertigation Technology for Transplanted Pigeonpea [Cajanus cajan (L.) Millsp.]. Legume Research. 42(2): 243-246.

\section{How to cite this article:}

Ajay Gokul, A. J., K. K. Shaheemath Suhara and Sheeja, P. S. 2020. Standardization of Irrigation and Fertigation Requirement for Amaranthus under Polyhouse. Int.J.Curr.Microbiol.App.Sci. 9(04): 490-493. doi: https://doi.org/10.20546/ijcmas.2020.904.058 